American Research Journal of Physics

ISSN: 2380-5714

Volume 4, Issue 1, 12 pages

AMERICAN RESEARCH JOURNALS

An Academic Publishing Hause

Research Article

Open Access

\title{
Transient creep characteristics of Tin Base Alloy
}

\author{
M.Y. Salema , A.Z. Mohamed ${ }^{\mathrm{b}}$ \\ a,* Physics Department, Faculty of Science, New Valley, Assuit University, 72511, El-Kharga, Egypt. \\ ${ }^{b}$ Physics Department, Faculty of Science, Zagazig University, Zagazig, Egypt. \\ mahmoud_salem569@yahoo.com
}

\begin{abstract}
Transient creep experiments were inspected under several used stresses extended from 10 to 19.5 MPa for three ternary eutectic (Sn-3.5Ag- xIn) alloys, where $\mathrm{x}$ takes the values ( $\mathrm{x}=0.5,1$ and $1.5 \mathrm{In})$. All tests at temperatures, ranging from 303 to $393 \mathrm{~K}$. The transient creep is classified by $\varepsilon \mathrm{tr}=\beta \mathrm{tn}$, Where $\varepsilon \operatorname{tr}$ and $\mathrm{t}$ are the transient creep strain and time. The exponent $\mathrm{n}$ was found to have values extended from 0.646 to 1.59 for Sn-3.5Ag-0.5In, ranging from 0.82 to 1.64 for the second alloy Sn-3.5Ag-1In, and finally it ranging from 0.94 to 1.74 for Sn-3.5Ag-1.5In. The value of $\beta$ was found to have values ranging between -14.38 to $-7.2,-13.85$ to -7 , and -13.55 to -6.8 for the three alloys; the activation enthalpy shows that the operating mechanism controlling the tin process may be the grain bounding diffusion. Also, X-ray diffraction examination display the permanence of both $\beta$-Sn rich phase and the intermetallic compound Ag3Sn and very little particles or residue from the intermetallic composition $\gamma$-In Sn4.
\end{abstract}

Keywords: Binary alloy; intermetallic composition; transient creep; ternary alloys.

\section{INTRODUCTION}

The transient creep distortion is specified by the motion of mobile dislocations and finish in their effective locking at obstacles or is originally believed as dislocation consuming source ${ }^{(1)}$. Tin-indium alloys are of individual importance, because the existence of indium appears to confer the special properties of wetting and bounding (2) to glass or glazed surfaces, and gives an increase of the low hardness and the resultant low mechanical strength of $\mathrm{Sn}{ }^{(3)}$. These alloys called Pewters (alloys of more than $90 \% \mathrm{Sn}$ ) are utilized especially as solders for packing and interconnection in the electrical, electronic, owing to their ease of fabrication into any needed form. Also, these alloys are used for utensils; they have been investigated ${ }^{(4,5)}$. Few publications (not many) dates in literature in the mechanical properties of Sn-In alloys, and Sn-Ag-In alloys have been done.

The aim of the present work is destined to give some information about mechanical and structure properties of the present alloy Sn-Ag-X In.

\section{EXPERIMENTAL}

The Sn-3.5Ag-0.5In, Sn-3.5Ag -1.0In, and Sn-3.5Ag -1.5In alloys or (Sn-Ag-xIn) where (x=0.5, 1.0, and 1.5) were prepared from Sn (purity 99.99\%) and Ag (purity 99.99\%) and high purity Indium (4N or 99.99\%). The ingots were rolled to wires (radius $0.4 \mathrm{~mm}$ ), and $5 \mathrm{~cm}$ gauge length. In this study the wires of Sn- Ag-In alloys were annealed at $453 \mathrm{~K}$ for $2 \mathrm{~h}$ to eliminate the cold work introduced during swaging and then slowly cooled to room temperature at a steady cooling rate $\mathrm{T}^{\prime}=2 \times 10^{-3} \mathrm{~K} / \mathrm{sec}$. After this heat treatment for all samples; they were considered to be completely precipitated ${ }^{(6)}$. Creep deformations were completed on annealed wire samples. The softly cooled samples were crept under fixed applied stresses (from $10 \mathrm{MPa}$ up to $19.5 \mathrm{MPa}$ ). These tests were achieved in an amended model of creep machine provided with computer. The accuracy of temperature measurement is of the order of $\pm 1 \mathrm{~K}$. Strain measurement were do with an accuracy of $\pm 1 \times 10^{-5}$. Energy-dispersive X-ray spectroscopy (EDS) analysis is used for chemical characterization of the used sample; the acquired results from EDS analysis are corresponding to tested alloys as shown in Table 1 and Fig.3. A 
Transient creep characteristics of Tin Base Alloy

solution of $2 \% \mathrm{HCl}, 3 \% \mathrm{HNO}_{3}$ and $95 \%$ (vol.\%) ethyl alcohol was prepared and used to etch the samples. Phase identification of the used samples accomplished out by X-ray diffractometry (XRD) at $40 \mathrm{KV}$ and $20 \mathrm{~mA}$ using $\mathrm{Cu} \mathrm{K} \alpha$ radiation with diffraction angles $(2 \theta)$ from $20.99^{\circ}$ to $99.99^{\circ}$ and a fixed scanning speed of $1^{\circ} / \mathrm{min}$.

Table1. Actual compositions of the experimental alloys, wt.\%..

\begin{tabular}{|c|c|c|c|}
\hline Experimental alloys & Sn & In & Ag \\
\hline Sn-3.5Ag-0.5In & 96 & 0.5 & 3.5 \\
\hline Sn-3.5Ag-1.0In & 95.5 & 1 & 3.5 \\
\hline Sn-3.5Ag-1.5In & 95 & 1.5 & 3.5 \\
\hline
\end{tabular}
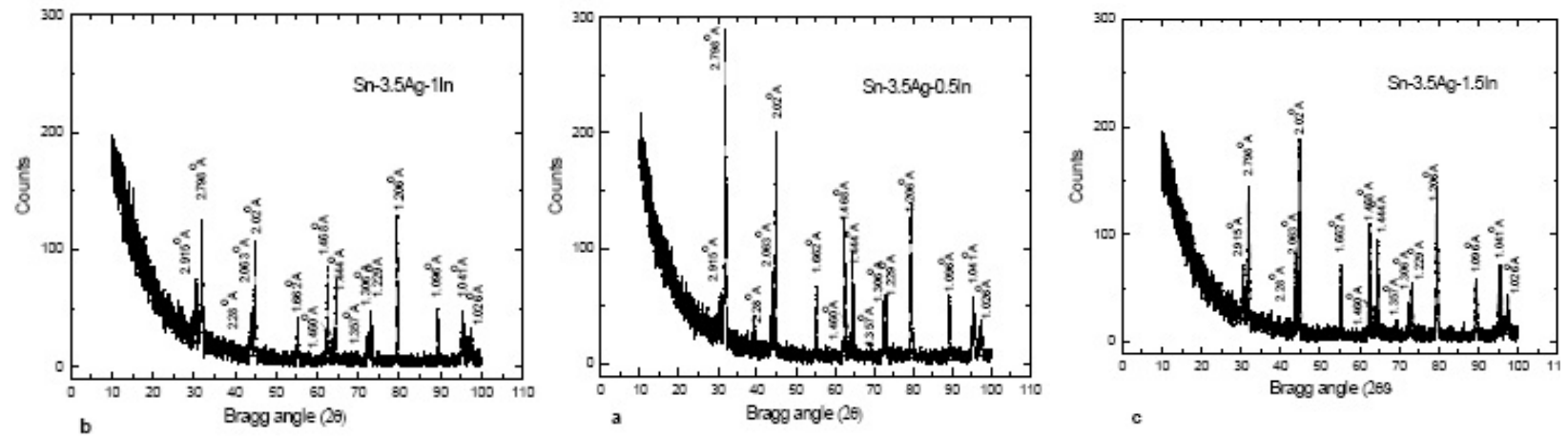

Figures1. XRD pattern for tested alloys; they are mainly composed of two phase structure, that is, tetragonal $\beta$-Sn rich phase, and the intermetallic compounds as Ag3Sn phase.

\section{RESULTS AND DisCUSSION}

The test of the X-ray diffraction model has been given in Fig.1; it displayed that Sn-3.5Ag-0.5In, Sn-Ag1.0In, and Sn-3.5Ag-1.5In alloys shows only two phase structure, that is, $\beta$-Sn rich phase. In addendum to the intermetallic compounds as $\mathrm{Ag} 3 \mathrm{Sn}$ is the other phase.

The transient strain is given by the equation $(1)^{(7)}$ :

$$
\varepsilon_{\mathrm{tr}}=\beta \mathrm{t}^{\mathrm{n}}
$$

where $\varepsilon_{\text {tr }}$ and $t$ are the transient creep strain, and time, $\beta$ and $\mathrm{n}$ are constants relying on the empirical experience states.
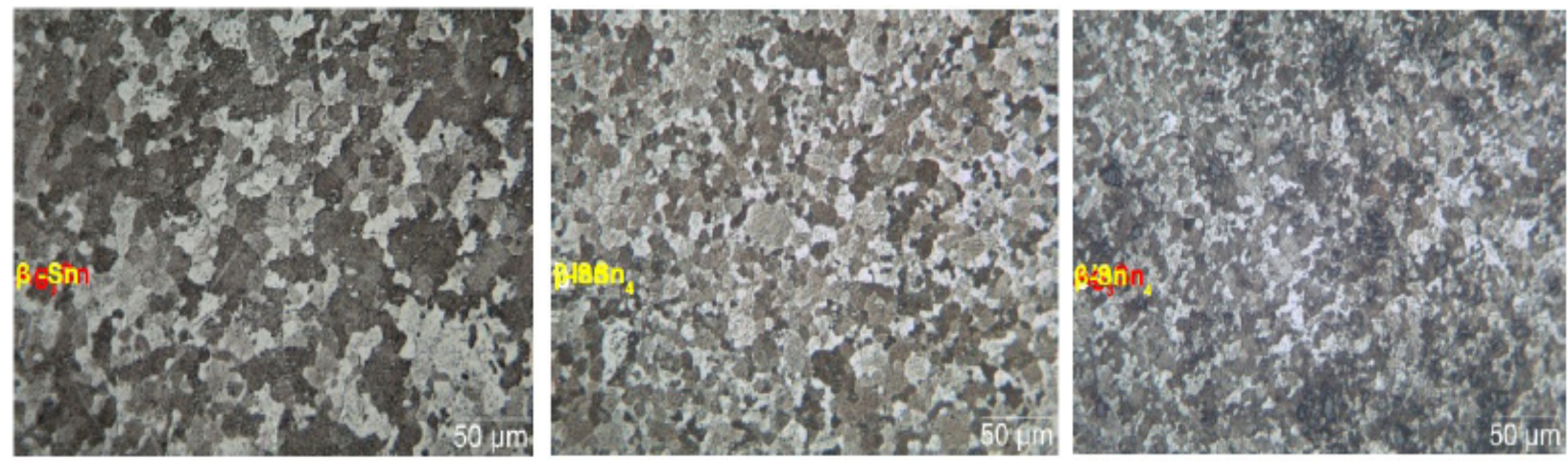

Figure2. illustrated the OM micostructure a) binary Sn-3.5Ag, b) Sn-3.5Ag-0.5In c) ) Sn-3.5Ag-1.0In 

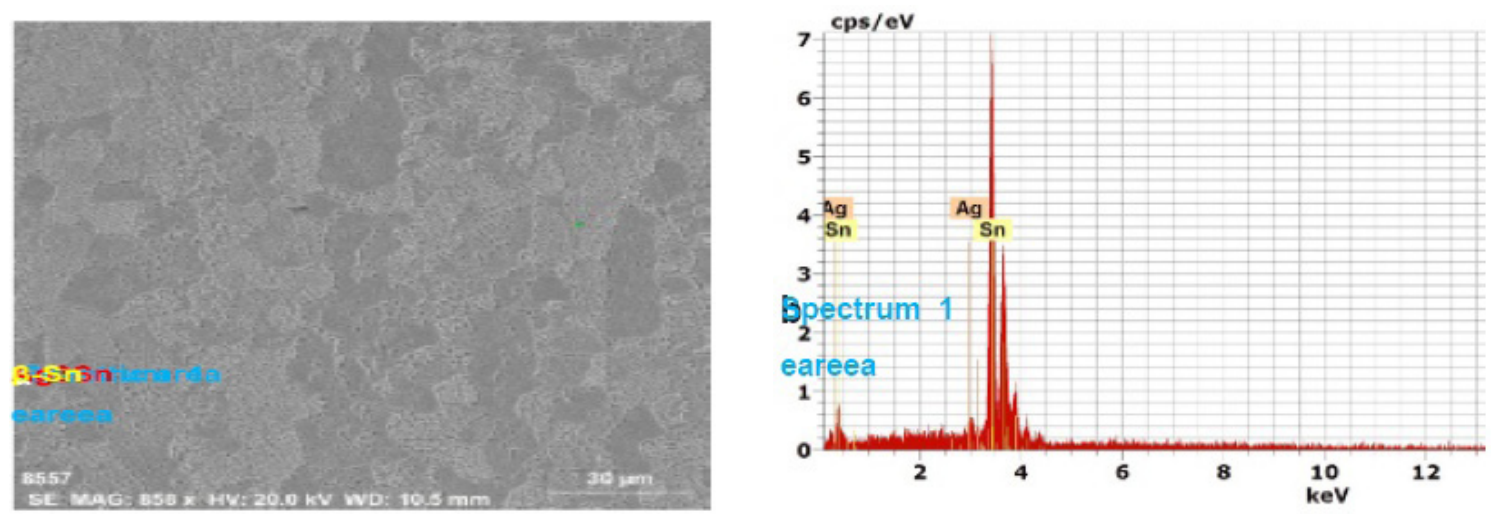

Spectrum: Acquisition

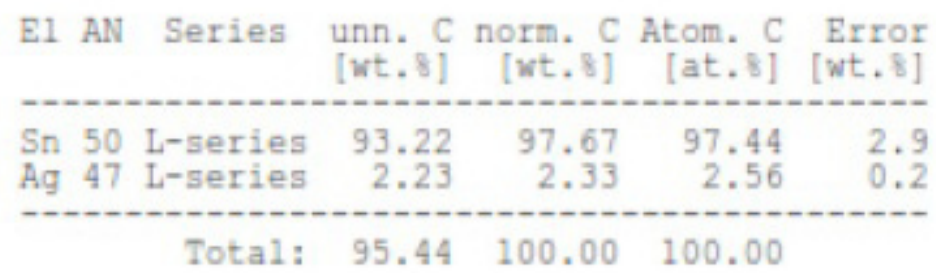

Figure3a. represented SEM images of the Sn-3.5Ag alloys, the microstructure composed of $\beta$-Sn areas, fine Ag3Sn precipitates, and eutectic area. In Fig.3.b, EDS analysis of the Sn-3.5Ag alloys.

It can be observed in Fig.2a that the microstructure of the $\mathrm{Sn}-3.5 \mathrm{Ag}$ binary alloy consists of relatively fine $\mathrm{Ag}_{3} \mathrm{Sn}$ precipitates in the white $\beta$-Sn matrix In Fig.2b, the microstructure of the Sn-3.5Ag-0.5In alloy showed a coarse $\gamma$ - $\mathrm{InSn}_{4}$ in the $\beta$-Sn matrix. Fig.2c represented the microstructure of Sn-3.5Ag-1.0In alloy, where the volume fraction of $\gamma$ - $\mathrm{InSn}_{4}$ is increased, in addition to, fine $\mathrm{Ag}_{3} \mathrm{Sn}$, and $\beta$-Sn matrix. Fig.3a; represented SEM images of the Sn-3.5Ag alloys, $\mathrm{m}$ the microstructure possessed $\beta$-Sn areas, fine $\mathrm{Ag}_{3}$ Sn precipitates, and eutectic area. In Fig.3-b EDS analysis of the Sn-3.5Ag alloys.

\section{Creep curves of Sn-3.5Ag -In alloys}

Fig.4a-e displays typical creep curves of the three tested solder alloys expressed as creep rate versus time at constant test temperature in the rang from 303 to $393 \mathrm{~K}$ in $20 \mathrm{~K}$ growing under applied stress level in the range of 10.5 to $19.5 \mathrm{MPa}$ for all tested materials. Typical examples of creep curves of alloys are presented in this Fig.
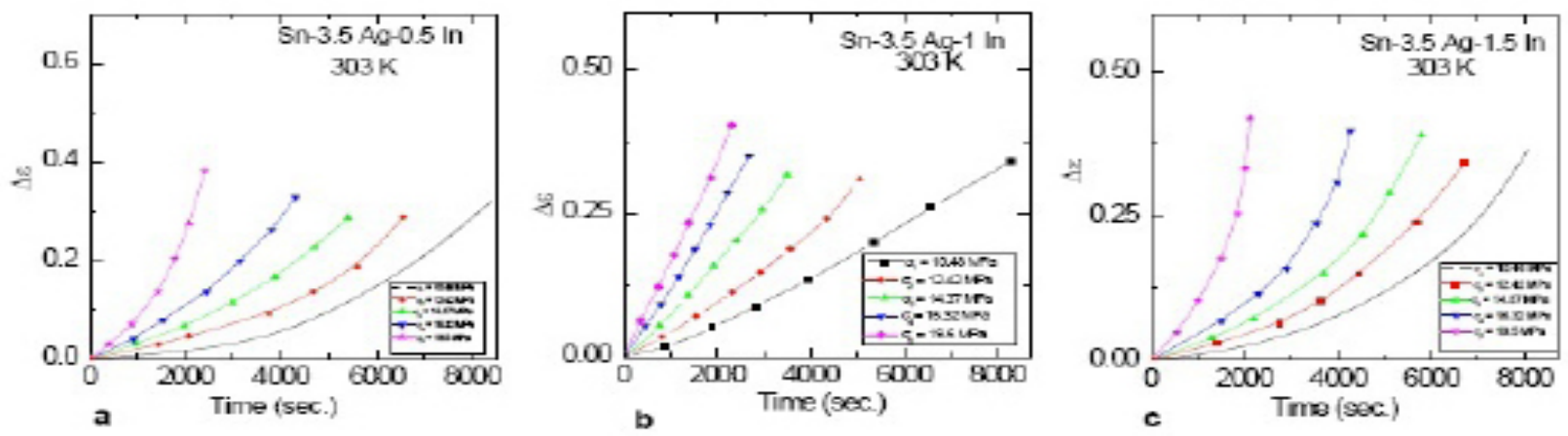

Figure4(a). Creep curves at $303 \mathrm{~K}$ and different applied stresses for Sn-3.5Ag-0.5In, Sn-3.5Ag-1In, and Sn-3.5Ag-1.5In ternary alloy. 
Transient creep characteristics of Tin Base Alloy
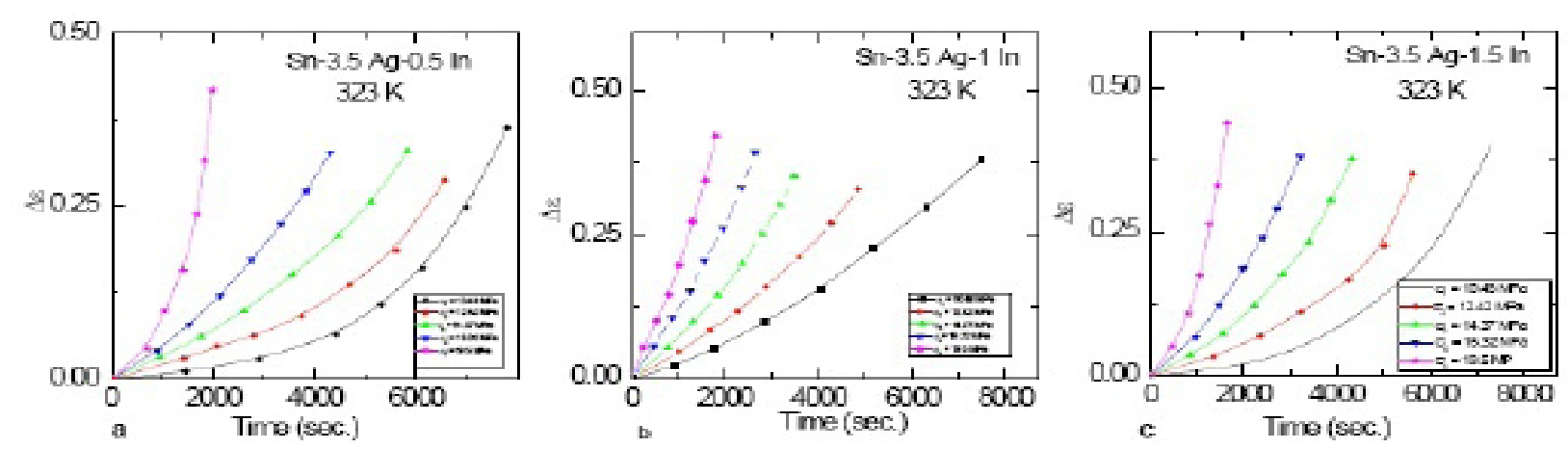

Figure4b. Creep curves at $323 \mathrm{~K}$ and different applied stresses for Sn-3.5Ag-0.5In, Sn-3.5Ag-1In, and Sn-3.5Ag-1.5In ternary alloy.
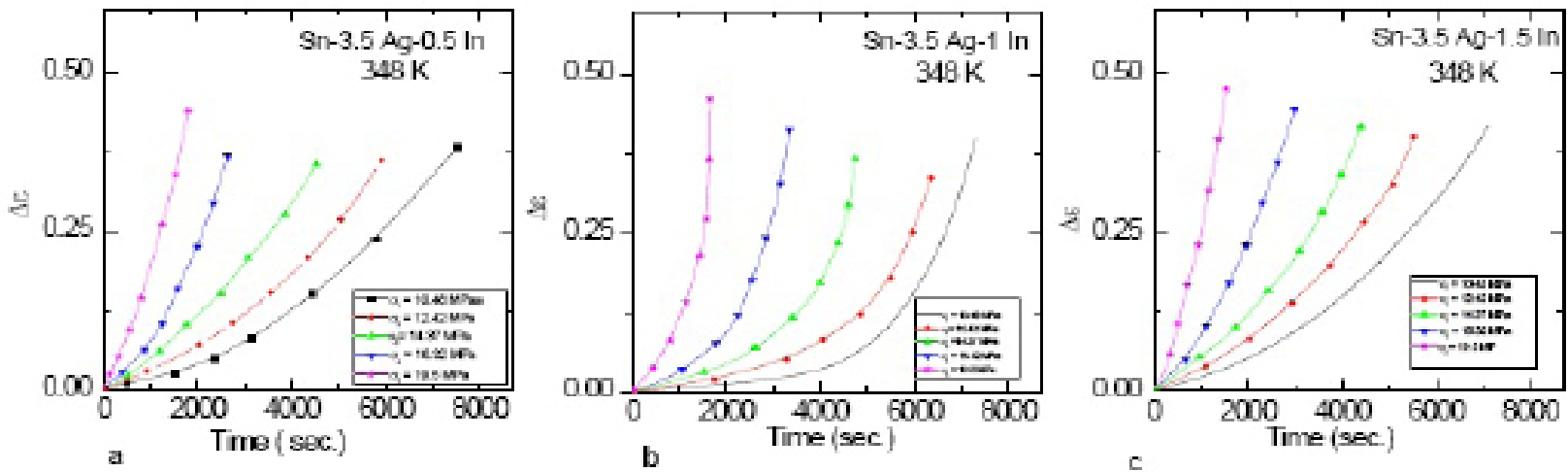

Figure4c. Creep curves at $348 \mathrm{~K}$ and different applied stresses for Sn-3.5Ag-0.5In, Sn-3.5Ag-1In, and Sn-3.5Ag-1.5In ternary alloy.
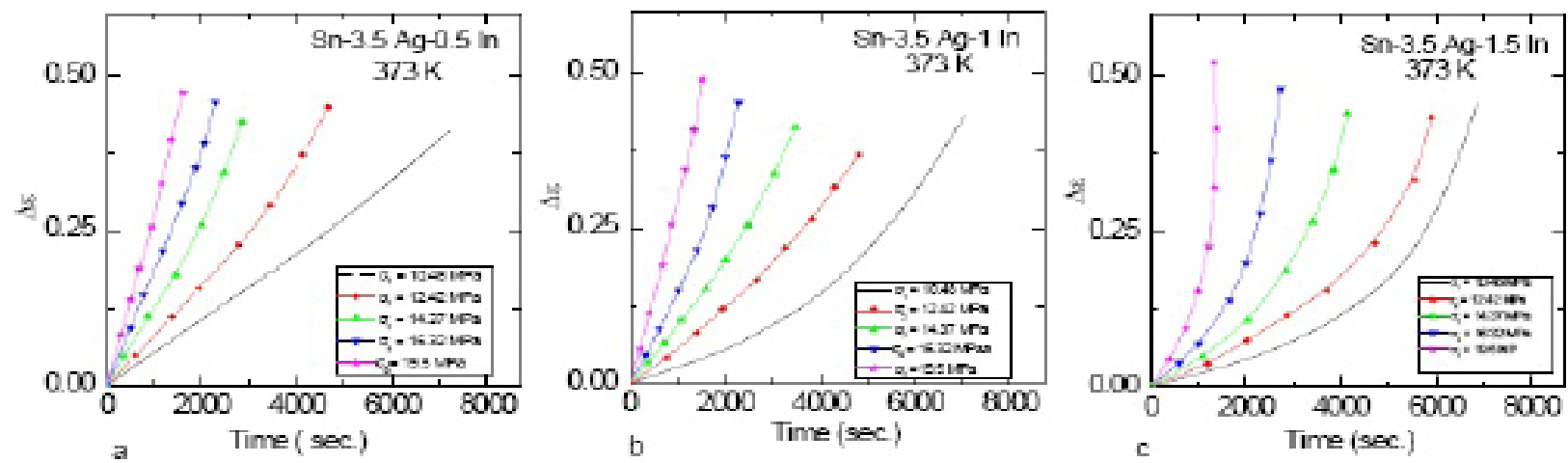

Figure4d. Creep curves at $373 \mathrm{~K}$ and different applied stresses for $\mathrm{Sn}-3.5 \mathrm{Ag}-0.5 \mathrm{In}, \mathrm{Sn}-3.5 \mathrm{Ag}-1 \mathrm{In}$, and Sn-3.5Ag-1.5In ternary alloy.

To compare the effect of small addition of In on Sn-3.5Zn lead-free solder alloys in the present study, Fig.5 represented the creep curves of the three tested alloys at constant stresses $=14.37 \mathrm{MPa}$, it is obvious that the ternary Sn-3.5Zn-1.5In alloys is more superplastic than the Sn-3.5Zn-1In, and Sn-3.5Zn-0.5In.

The relation between $\ln \varepsilon_{\mathrm{tr}}$ and lnt gives straight lines as shown in Fig.6a-e. This research denote that there is transition temperature under $50{ }^{\circ} \mathrm{C}$. 
Transient creep characteristics of Tin Base Alloy
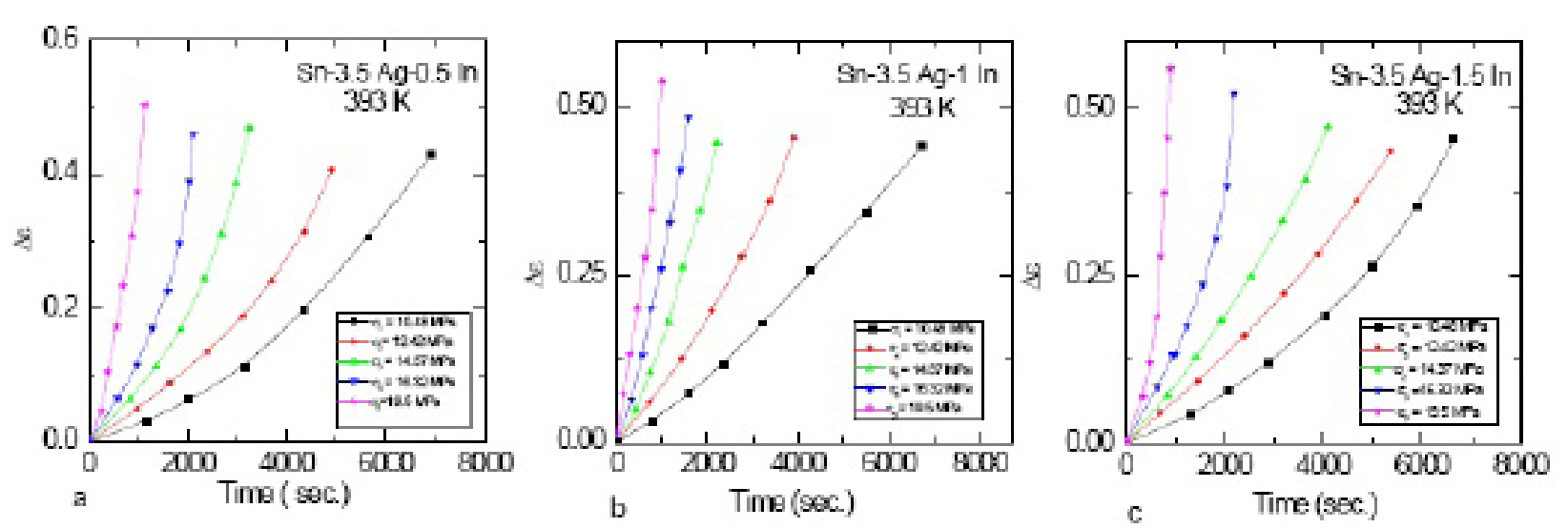

Figure4e. Creep curves at $393 \mathrm{~K}$ and different applied stresses for Sn-3.5Ag-0.5In, Sn-3.5Ag-1In,and Sn-3.5Ag1.5In ternary alloy.
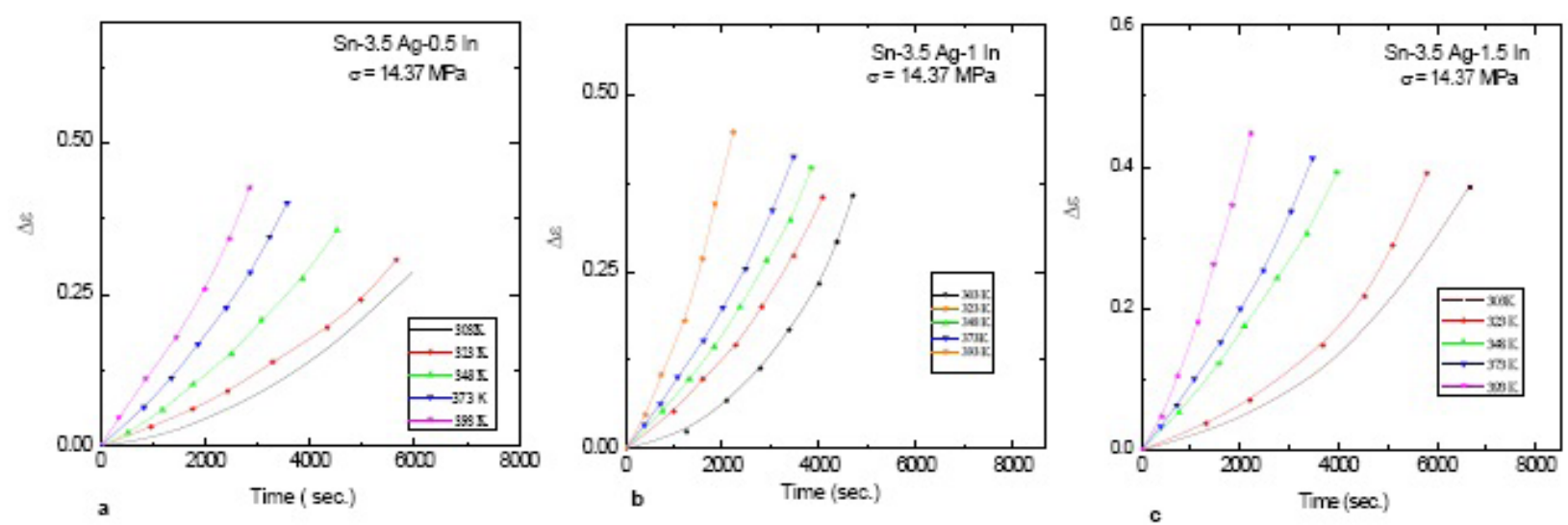

Figure5. Comparison of isothermal creep curves at constant stress $=14.37$ MPa and different temperature for the three tested ternary alloys.
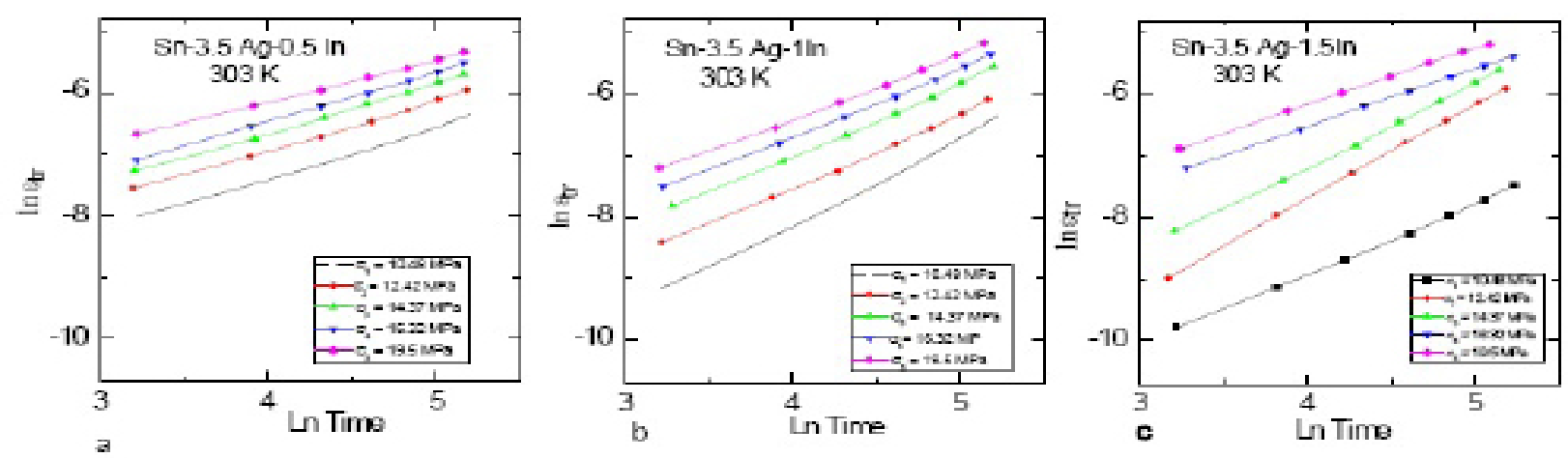

Figure6a. Relation between Inetr and Int for Sn-3.5Ag-0.5In, Sn-3.5Ag-1In,and Sn-3.5Ag-1.5In ternary alloy, at $303 \mathrm{~K}$ and different stresses. 

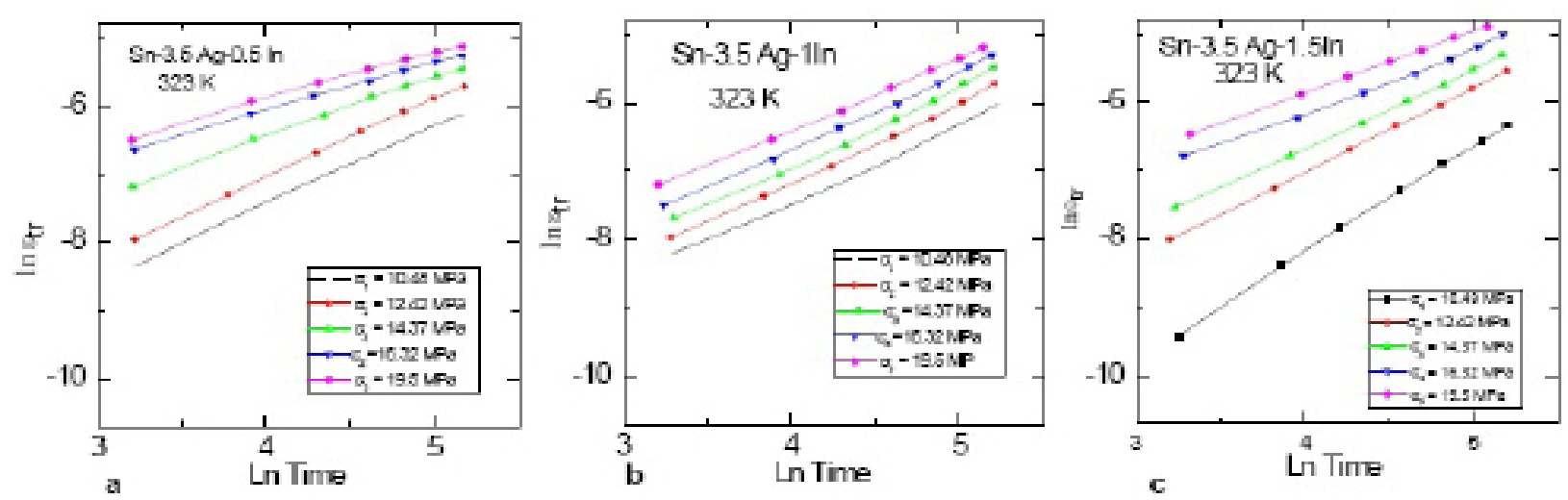

Figure6b. Relation between Inetr and Int for Sn-3.5Ag-0.5In, Sn-3.5Ag-1In, and Sn-3.5Ag-1.5In ternary alloy, at $323 \mathrm{~K}$ and different stresses.
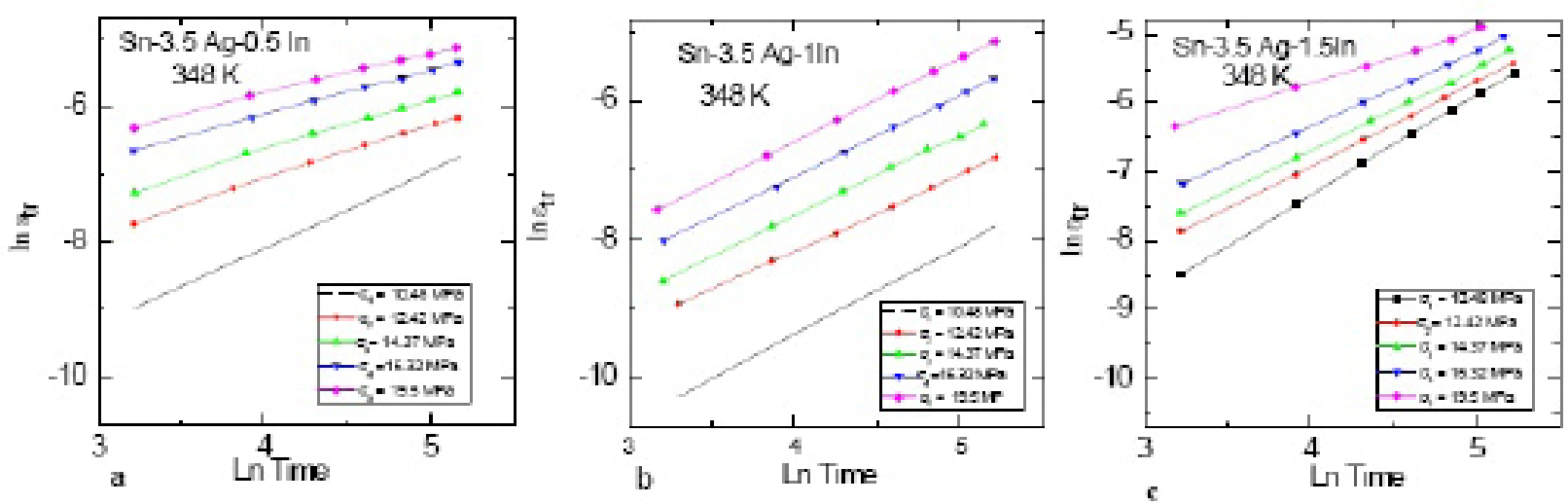

Figure6c. Relation between Inetr and Int for Sn-3.5Ag-0.5In, Sn-3.5Ag-1In, and Sn-3.5Ag-1.5In ternary alloy, at $348 \mathrm{~K}$ and different stresses.
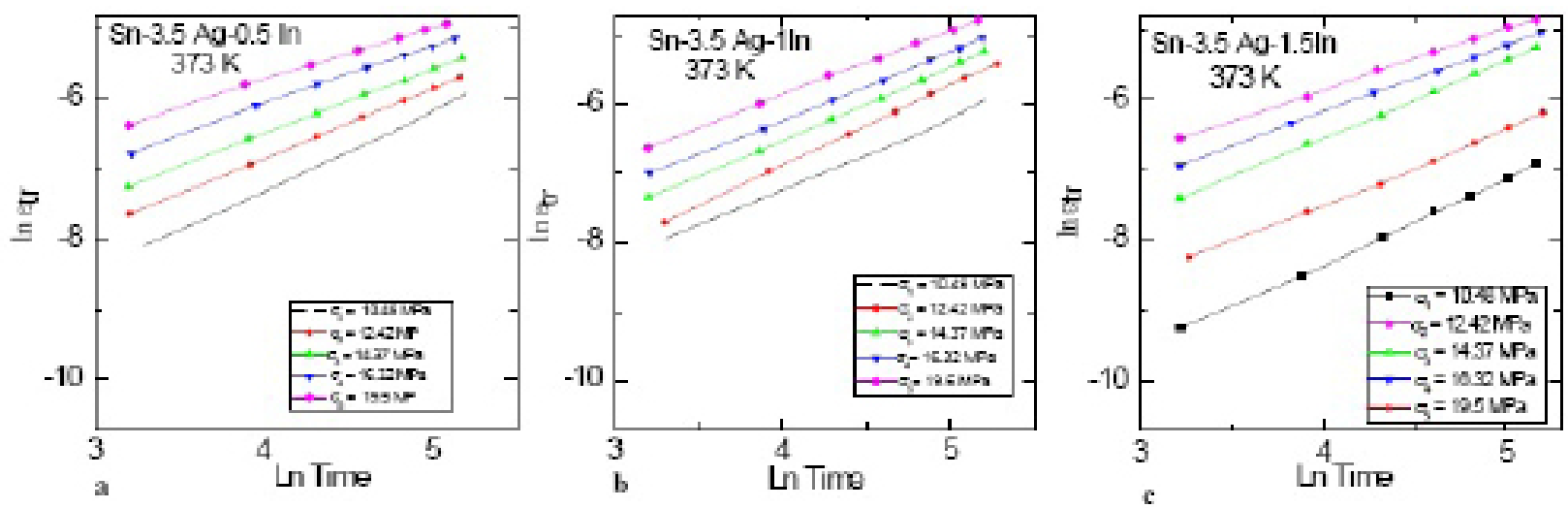

Figure6d: Relation between Inetr and Int for Sn-3.5Ag-0.5In, Sn-3.5Ag-1In, and Sn-3.5Ag-1.5In ternary alloy, at $373 \mathrm{~K}$ and different stresses. 
Transient creep characteristics of Tin Base Alloy
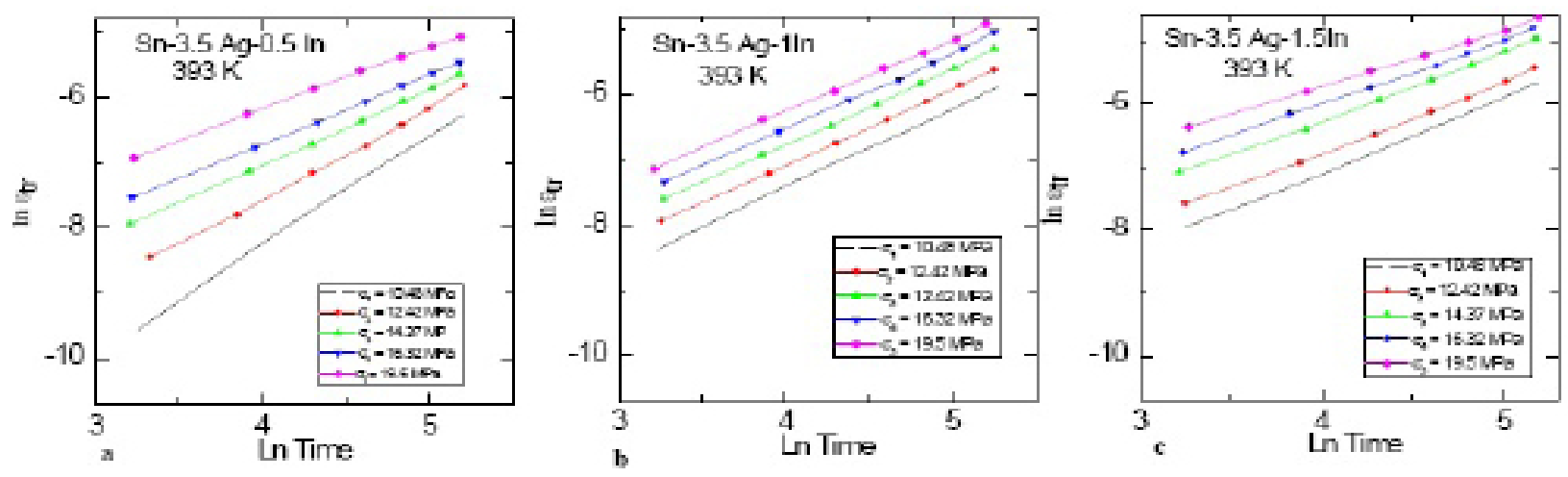

Figure6e. Relation between Inetr and Int for Sn-3.5Ag-0.5In, Sn-3.5Ag-1In, and Sn-3.5Ag-1.5In ternary alloy, at $393 \mathrm{~K}$ and different stresses.
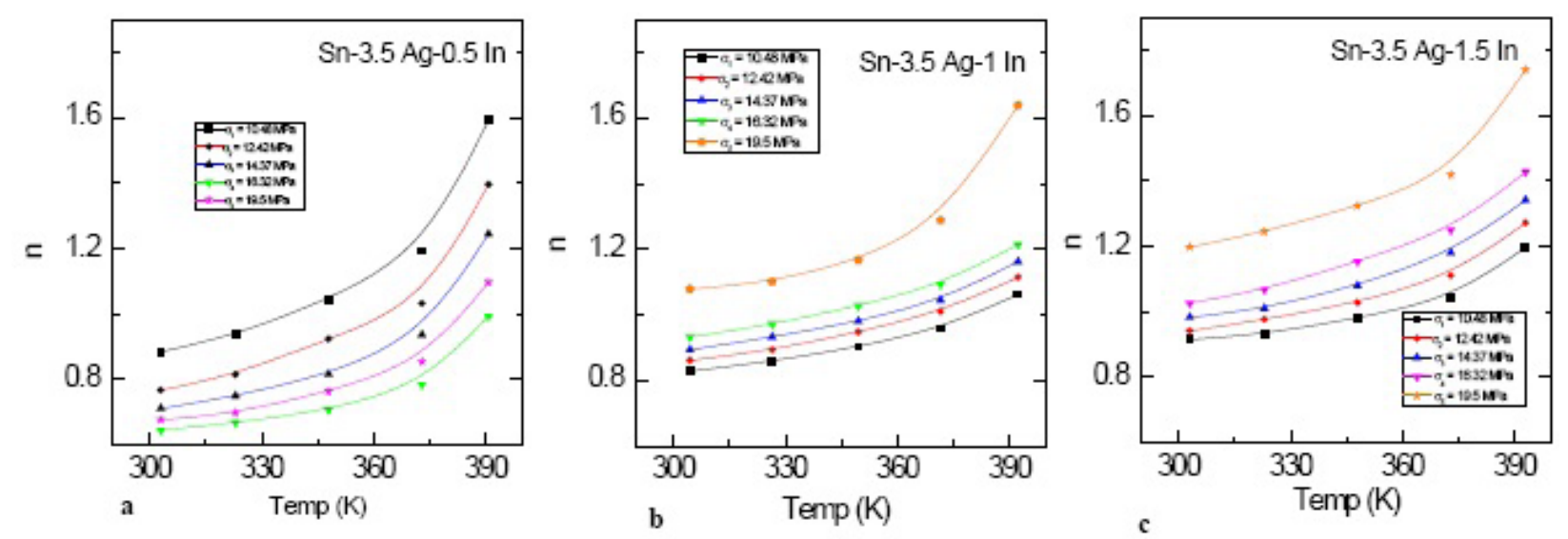

Figure7. The temperature dependence of the parameters, $n$, at different applied stresses for Sn-3.5Ag-0.5In, Sn-3 $.5 \mathrm{Ag}-1 \mathrm{In}$, and $\mathrm{Sn}-3.5 \mathrm{Ag}-1.5 \mathrm{In}$ ternary alloy.

On the other hand the exponent $n$ was estimated from the slope of these lines and was found to have values extended from 0.646 to 1.59 for Sn-3.5Ag-0.5In, ranging from 0.82 to 1.64 for the second alloy Sn-3.5Ag-1In, and finally it ranging from 0.94 to 1.74 for Sn-3.5Ag-1.5In as represented in Fig.7, and Table 2

Table2. Comparison of the transient creep characteristics of the tested alloys.

\begin{tabular}{|c|c|c|c|c|}
\hline Experimental alloys & $\mathrm{Q}(\mathrm{kJmol}-1)$ & $\gamma$ & $\beta$ & $\mathrm{n}$ \\
\hline Sn-3.5Ag-0.5In & $25: 28.5$ & $0.186: 0.29$ & $-14.38:-7.2$ & $0.646: 1.59$ \\
\hline Sn-3.5Ag -1In & $20.16: 25.3$ & $0.10: 0.21$ & $-13.85:-7$ & $0.82: 1.64$ \\
\hline Sn-3.5Ag -1.5In & $10.5: 15.48$ & $0.073: 0.12$ & $-13.55:-6.8$ & $0.94: 1.74$ \\
\hline
\end{tabular}

The intercepts of $\ln \varepsilon_{\mathrm{tr}}$ and $\ln t$ at $\operatorname{lnt}=0$ gave the transient creep parameter $\beta$; it was calculated from Eq.(2) ${ }^{(7,8)}$.

$$
\ln \beta=\left(\ln t_{2} \varepsilon_{t r 1}-\ln t_{1} \varepsilon_{t r 2}\right) / \ln t_{2}-\operatorname{lnt} t_{1}
$$

The value of $\beta$ was found to have values ranging between -14.38 to $-7.2,-13.85$ to -7 , and -13.55 to -6.8 for the alloys as shown from Fig.8. 
Finally the activation enthalpy of the transient creep $Q_{t r}$ was evaluated utilizing (4).

$$
\varepsilon_{\mathrm{tr}}=\varepsilon_{0}+\mathrm{t}^{\mathrm{n}} \exp \left\{-\mathrm{Q}_{\mathrm{tr}} / \mathrm{KT}\right\}
$$
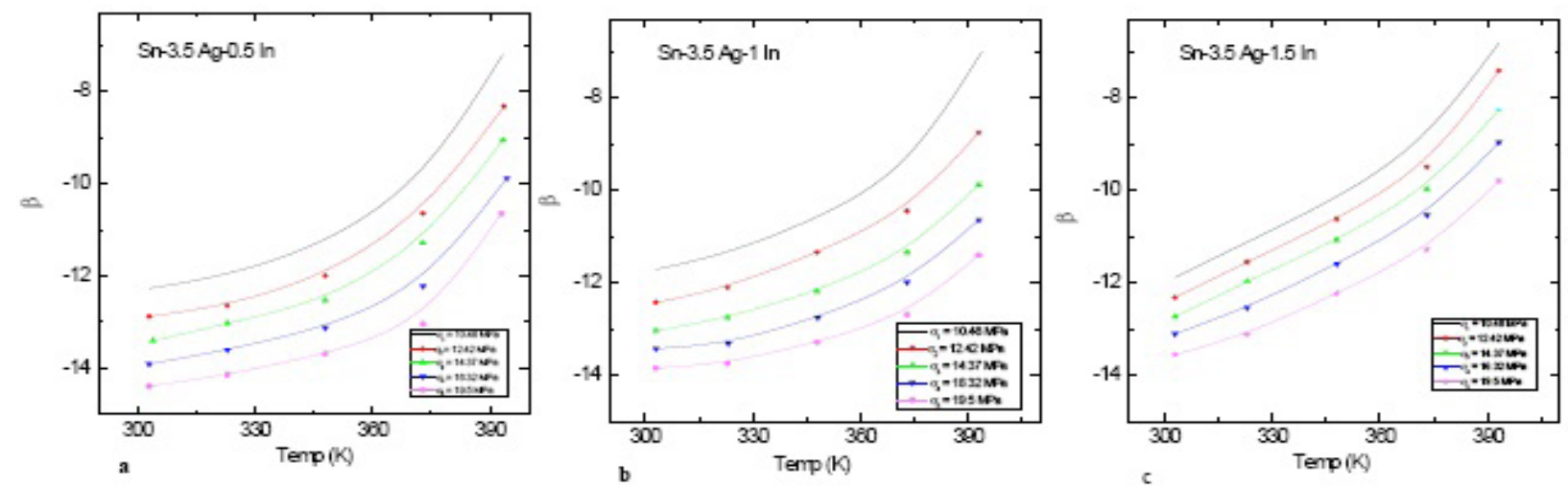

Figures8. The temperature dependence of the parameters, $\beta$, at different applied stresses for Sn-3.5Ag-0.5In, Sn3.5Ag-1In, and Sn-3.5 Ag-1.5In ternary alloy.

The activation enthalpy of the transient creep $Q_{\text {tr }}$ have been found to be $25: 28.5 \mathrm{KJ} / \mathrm{mol}$ to for $1^{\text {st }}$ alloy where ( $\mathrm{x}=0.5 \mathrm{In}$ ), 20.16: $25.5 \mathrm{KJ} / \mathrm{mol}$ for $(\mathrm{x}=1 \mathrm{In})$ and $10.5: 15.48 \mathrm{KJ} / \mathrm{mol}$ for the third alloy ( $\mathrm{x}=1.5 \mathrm{In}$ ) in the low and high temperatures regions respectively as represented in Figs.9,10, and Table 2
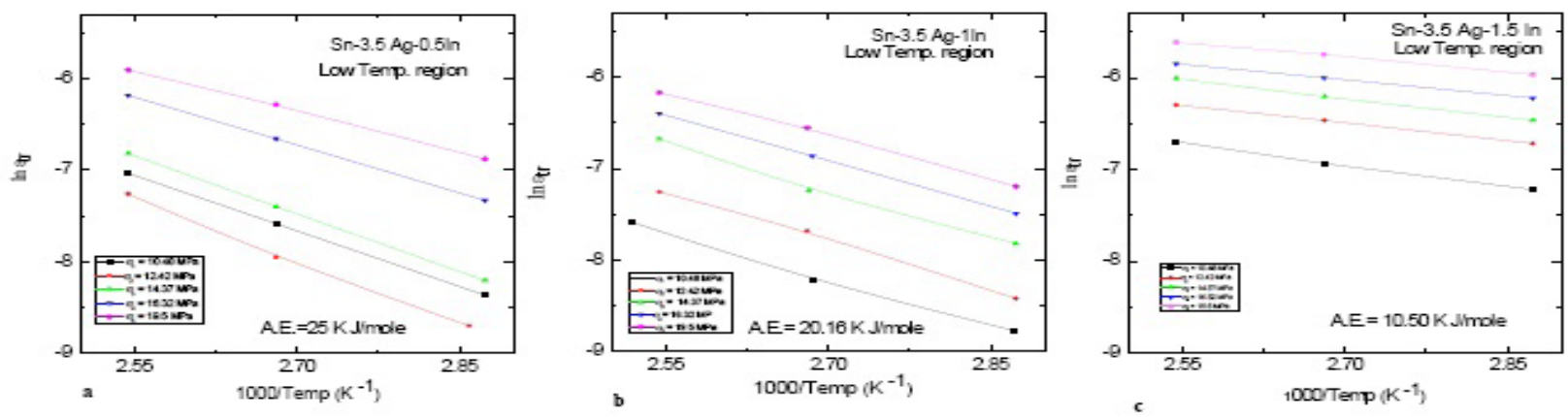

Figure9. Relation between Inetr and 1000/T at different applied stresses for Sn-3.5Ag-0.5In, Sn-3.5Ag-1In, and Sn-3.5Ag-1.5In ternary alloy, at low Temp.
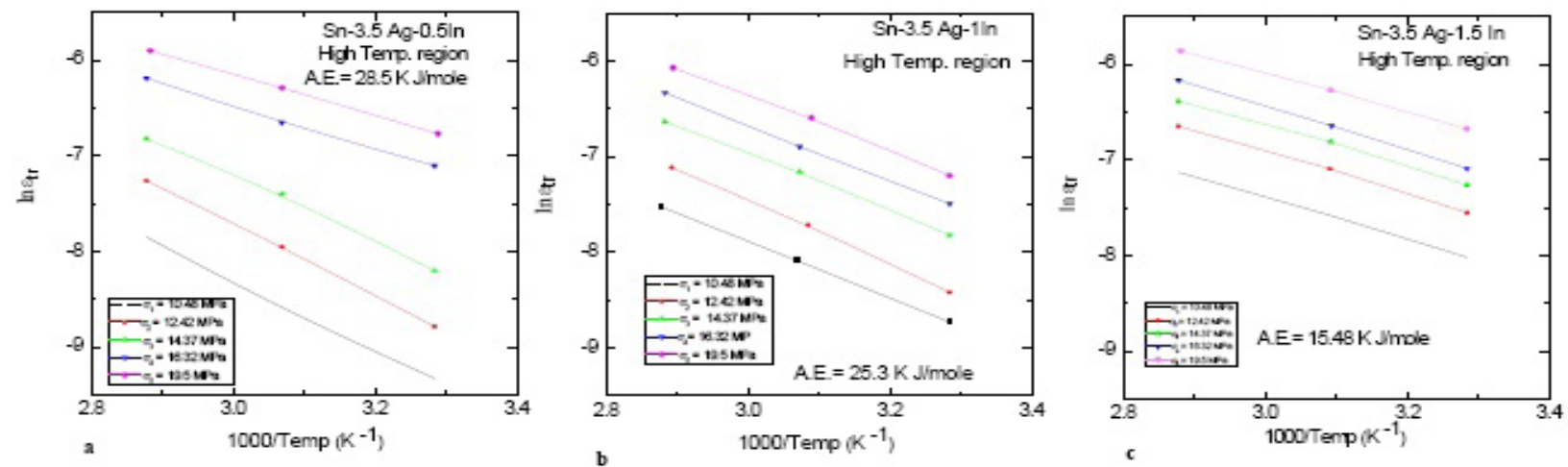

Figure10. Relation between Inetr and 1000/T at different applied stresses for Sn-3.5Ag-0.5In,Sn-3.5Ag-1In, and Sn-3.5Ag-1.5In ternary alloy, at high Temp. 
Creep is a persistent operation, since transient and steady-state creep regions are joined to each other by the equation $(3)^{(9,10)}$.

$$
\beta=\beta 0(\varepsilon \cdot s t)^{\gamma}
$$

where $\beta 0$ is a fixed and $\gamma$ is the steady-state creep exponent gauge the contribution of the transient technicality to the steady-state creep manner. The values of $\beta$ and $\varepsilon$ st qualify us to plot a relation between $\ln \beta$ and $\ln \varepsilon$ st as represented in Fig.11. A longitudinal reliance is obtained with intermediate value of $\gamma$ for the three alloys. This relatively value of $\gamma$ confirms that the mechanism dependable on the transient stage also operates in the steady-state stage. This average value of $\gamma$ is identical with those acquired by Kenawy et al. ${ }^{(11)}$; and Mahmoud and Graiss $^{(12)}$ in their study. The exponent $\gamma$ was found to change from 0.186 to $0.29,0.10$ to 0.21 , and 0.073 to 0.12 for the three alloys respectively; as shown in Table2.
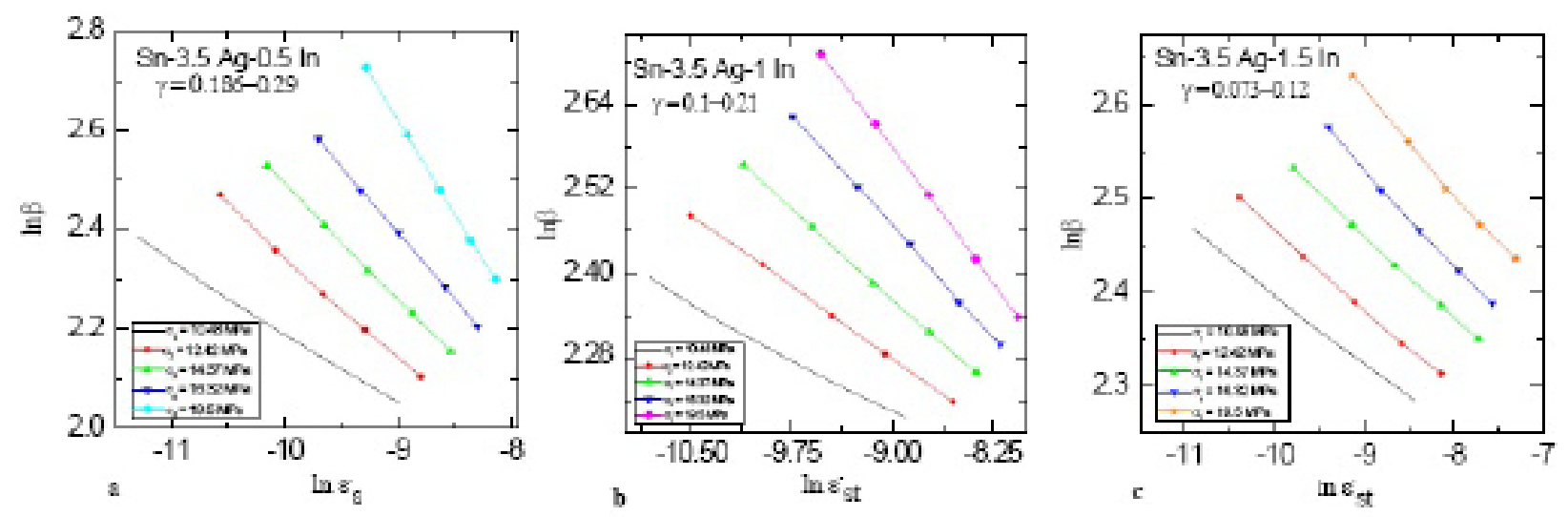

Figure11. Relation between In $\beta$ and lnc.st at different applied stresses for Sn-3.5Ag-0.5In, Sn-3.5Ag-1.0In, and Sn-3.5Ag-1.5In ternary alloy, at high Temp.

The elevate of parameter $\beta$ with elevation experiment temperature as presented in Fig. 6 is established on the fact that $\beta$ represents the precipitation reliance of $\varepsilon_{\mathrm{tr}}$ on the precipitation temperature ${ }^{(13,14)}$. So it could be pronounced that a rise of the working temperature helps dislocations to overcome the precipitates that act as barrier ${ }^{(15)}$. The driving force for both reconfiguration of these dislocation provenances and consuming of the opposite ones is quickened by the utilized stress which in addition to the effective energy oscillatory stresses facilitates the movement of dislocations parallel to the utilized stress orientation ${ }^{(16,17)}$. Also; the distinguish elevate in parameter $\beta$ could be due to the increase in the motion of groups of piled-up dislocations ${ }^{(18)}$ while the number of A Guinier-Preston zone (GP zones) is still fixed. Dislocations of increased mobility existing among a stable number of zones result in less of a pinning effect and, accordingly, dislocations become free and their movement must be easier. This guide to an excess in $\beta$. The observed development of $\beta$ can be because of the outward flexible energy provided thermally (through testing temperatures). This energy simplified the motion of existing dislocations between the courses of creep and shortens the duration of the creep process ${ }^{(19,20)}$.

Fig.12 showed the variation of d-spacing [A] , with $2 \theta$, the value of the angle varies from 22 to 99 for Sn-3.5Ag ternary Sn-3.5Ag -1In, and Sn-3.5Ag -1.5In alloys. Fig.13: Showed the variation of Rel. Int.[\%], with $2 \theta$ for same tested alloys. Fig.14; showed the variation of FWHM with $2 \theta$ for the same tested alloys.

It is obvious that activation energies for binary alloys are more than that of ternary Sn-3.5Ag-1In, and Sn-3.5Ag -1.5In alloys because of ternary alloys are more refine in grain size and superplastic than binary alloys. The activation enthalpies, point that the transient creep in the low temperature area is controlled by dislocation intersection, while at altitude temperatures, the dominant technique is grain boundary sliding ${ }^{(21)}$. 
Transient creep characteristics of Tin Base Alloy
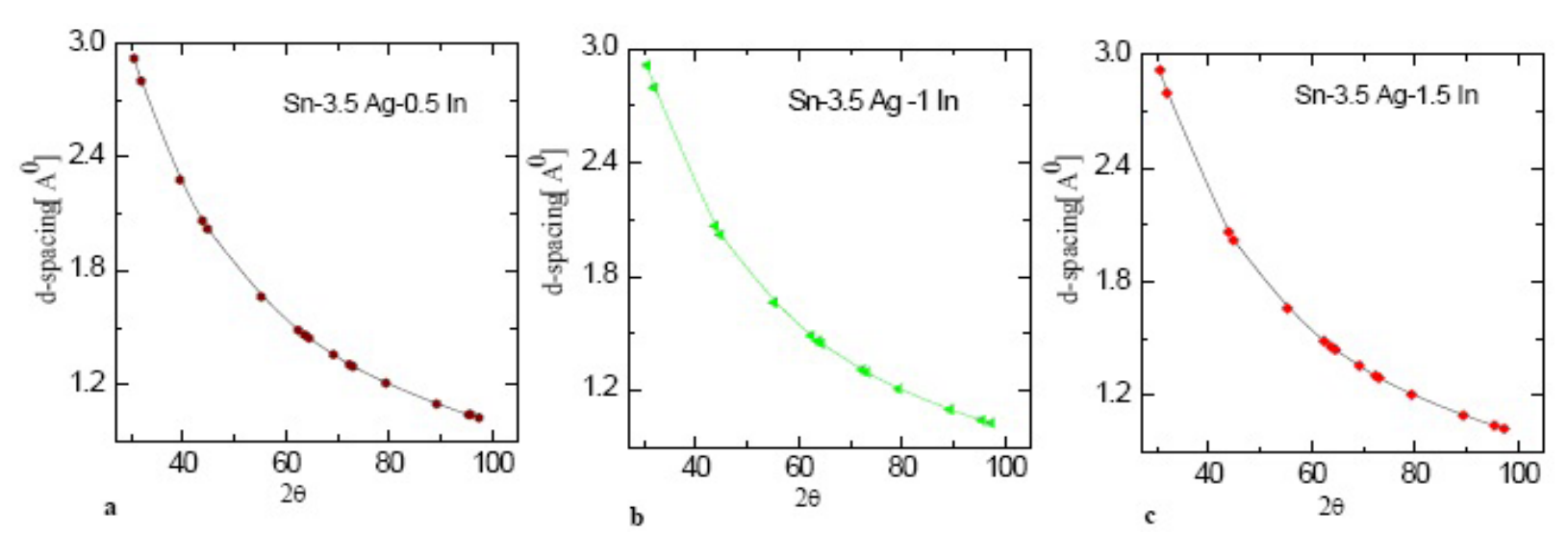

Figure12. Showed the variation d-spacing [A]], with $2 \theta$ for Sn-3.5Ag-0.5In, Sn-3.5Ag-1In, and Sn-3.5Ag-1.5In ternary alloy
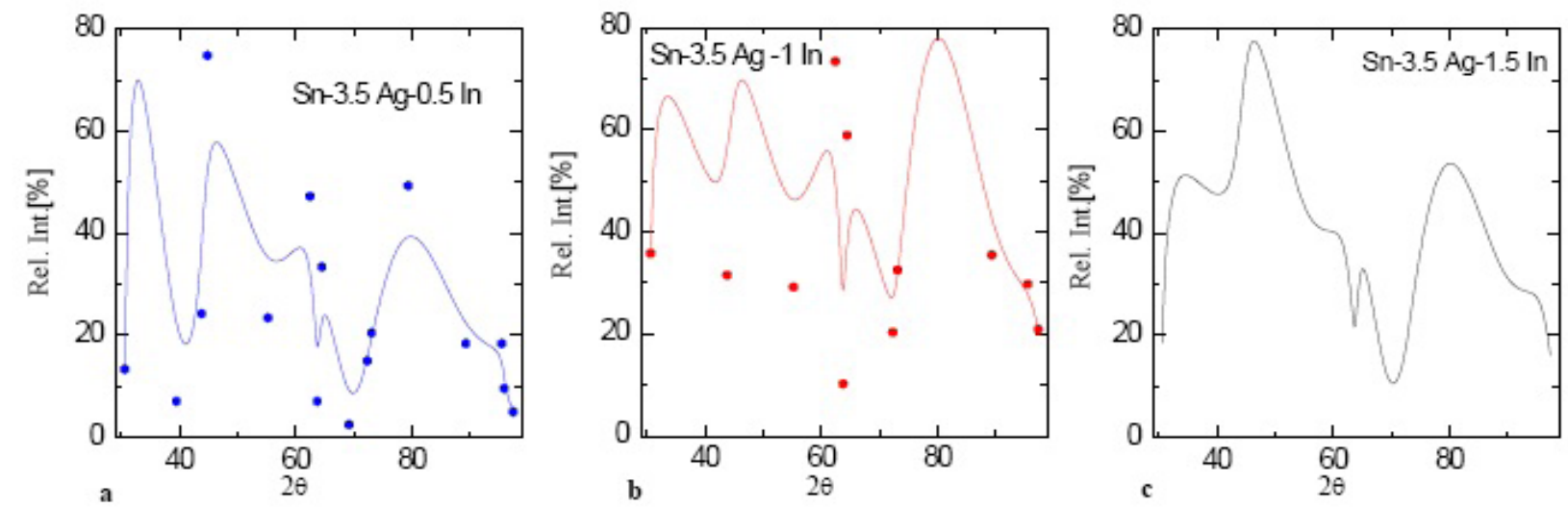

Figure13. Showed the variation of Rel. Int.[\%],2 $\theta$ for Sn-3.5Ag-0.5In, Sn-3.5Ag-1In, and Sn-3.5Ag-1.5In ternary alloy.
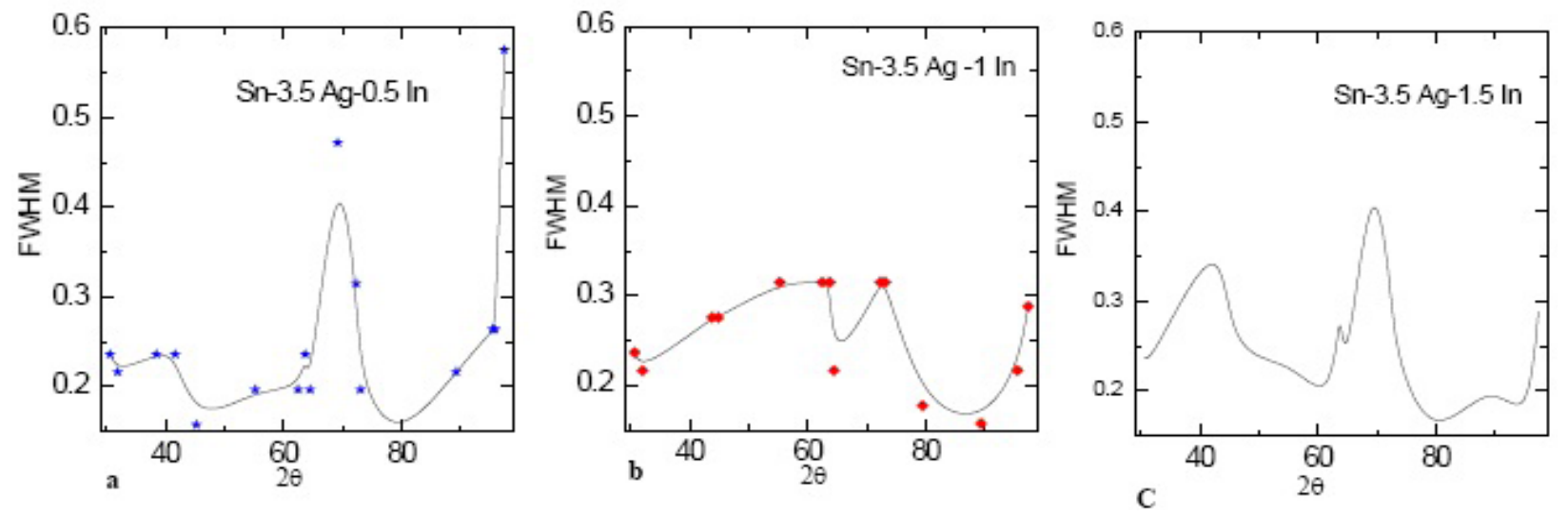

Figure14. Showed the variation of FWHM with $2 \theta$ for Sn-3.5Ag-0.5In, Sn-3.5Ag-1In, and Sn-3.5Ag-1.5In ternary alloy. 
It can be seen that, although each of single curves do not permanently showed a sharp primary creep stage they all eventually show a relatively short secondary region in which the load propagates longitudinal with time. Necking and fracture of all samples does not occur, there should not be a third stage as in the ordinary tensile creep test. Also, the tested alloy of tin base alloy under low working temperature obeys the logarithmic creep which obeys the equation $\varepsilon^{\prime}=\sigma \log$ t. The samples are so stable in texture (ternary) with precise grain size. The intermetallic compounds $\mathrm{Ag}_{3} \mathrm{Sn}$ as will be obtain by X-ray diffraction will precipitate within grain size and makes pining through the grains. The influence of indium content on the creep resistance of the tested Sn3.5Ag-0.5In alloys can be inferred from their respective microstructure.

\section{CONCLUSION}

This paper has inspected the effects of small amount of In on microstructure and creep properties of Sn-3.5Ag based lead-free solder alloys; the Conclusions are.

1-For transient creep stage, for all three samples, the activation energies estimated indicate that value of 0.5In is more than that of $1 \mathrm{In}$ and $1.5 \mathrm{In}$, therefore the first samples is lower elongation than the two other.

2- The values of $\gamma$ submit a high reliance of steady-state creep on the transient creep stage.

3-The transient creep parameter $\mathrm{n}$ and $\beta$ rises with rising the distortion temperature and loads.

4- Addition of In to the $\mathrm{Sn}$ matrix led to; the structure fine $\mathrm{Ag}_{3} \mathrm{Sn}$ precipitates in the white $\beta$-Sn matrix, in addition to eutectic areas.

\section{REFERENCES}

1. Mott NF, and Nabarro FR. Strength of Solids. 1984; Pro. Bristol Conf. Phys. Soc.; 50-51.

2. Al-Gananiy GS, Nagy MR, Khalifa BA, Afify R. Creep and Structure Parameters Near the Transformation Temperature of Sn-1 wt\% Pb Alloy. 2002; Phys. Stat. Sol. (a), 193 (2): 22-235.

3. Barry BTK. and ThwAaites C D. Tin- Its Alloys and Compounds, Wiley, New York (chaps 3,4) 1983.

4. Al-Gananiy G. S, Creep and Structure Parameters Near the Transformation Temperature of Sn-1 wt\% Pb Alloy. 2011phys. Stat. Sol., Physical, Review, A Volume: 84: 1020-1024.

5. Al-Gananiy G. S, and Mostafa M. T. Grain Size Dependence of Steady State Creep Rate in Sn-1 wt\% Zn Alloy. 2000; Egypt, J , solids 23: 333-340.

6. Saker MS. Mohamed A Z. etal, 1998, Egypt. J. solids B2 ,34. (a)169: 217.

7. M.Y.Salem; Effects of $\mathrm{Cu}$ addition on creep characteristics of Sn-9Zn lead-free solders; Egypt. J. Solids, Vol. (39); 2016, 107-121.

8. El-Daly AA., Abdel-Daiem AM., Yousf M. Transient creep characteristics in two Pb-Sn-Zn ternary alloys. 2001; Materials Chemistry and Physics 71: 111-119.

9. Al-Ganainy GS., Mostafa MT., and Nagy M. R. Effect of Temperature and Stress on the Structure and Creep Parameters of $\mathrm{Pb}-2$ at\% Sb Alloy phys. stat. sol. (a). 1998, 165, 185.

10. Yoessef SB, Fawzy A, Sobhy M, and Saad G. Creep Behaviour Of Al-10wt.\%Zn Alloys With Different Grain Diameter In The High Stress Region. 1993; Acta Phys. Slov. (43). No.6: 431- 440.

11. Kenawy MA, Sakr MS, Sakr EM, Zayed HA, and Mourad NO. Transient and Steady State Creep of Al 4.5 wt\% Mg During Phase Transformation. 1990: phys. stat. sol. (a) 121, 467.

12. Mahmoud MA, Graiss G, Effect of Superimposed Oscillations on the Creep Characteristics of Al-22 wt\% Ag Alloy.2002; J. Mater. Sci: 37, 2215-2223. 
Transient creep characteristics of Tin Base Alloy

13. Nagy MR, Abd El-Salam F, Habib N. D, Kamel R. Plastic deformation of Al-4.5 wt\% Cu and Al-4.5 wt $\%$ $\mathrm{Cu}-0.1 \mathrm{wt} \%$ In alloys under the effect of cyclic stress reduction. 1981; Czech. J. Phys.; 31, 939.

14. Nagy MR, Saker MS, Kamel R. 1981; Transient Creep Characteristics Near the Transformation Temperatures of Al-5wt\%Zn and Al-15wt\%Zn Alloys Indian J. Phys.; A 55, 179 .

15. C.V.Singh, A.J.Mateos, D.H.Warner; Atomistic simulations of dislocation-precipitate interactions emphasize importance of cross-slip, Scripta, Metall.,Vol.64,ssue 2011,398-401.

16. Abd El-Salam F, Abd El-khalekh AM., and Nada R. H. Phase characteristics of pre-deformed Al-40 wt\% Zn alloy. 2000; Eur. Phys. J.; 12, 159.

17. Kocks U F. On the mechanism of anomalous slip in bcc metals. 2010; J. Eng, Mater J. Eng. Mater and Technol; 98(1), 76-85.

18. Meleka AH, Evershed AV, The character of some of the creep-fatigue interactions in metals. 1960: J. Inst. Metals; 88, 411

19. Mark Whittaker, Will Harrison, Christopher Deen, Cathie Rae, Steve Williams. Creep Deformation by Dislocation Movement in Waspaloy. 2017; Journal of Materials (Basel), Vol. 10(1): 61.

20. Graiss G, Mahmoud MA, Ashry AH, Abd El-Khalek AM, and Abd El-Rehim AF. Plastic Deformation of Al-4.5 $\mathrm{wt} \% \mathrm{Cu}$ and $\mathrm{Al}-4.5 \mathrm{wt} \% \mathrm{Cu}-0.1 \mathrm{wt} \%$ In Alloys under the Effect of Cyclic Stress Reduction. 2004; Phys. Stat. Sol. (a) 201, No. 10: 2295-2304.

21. Yousf Salem M. Transient and steady-state creep characteristics of Transformations in Al-Zn Binary Alloys. 2017; International Journal of New Horizons in Physics Vol. 4, No.2 21-33.

Citation: M.Y. Salema, A.Z. Mohamed. "Transient creep characteristics of Tin Base Alloy", American Research Journal of Physics, vol 4, no. 1, 2018, pp. 1-12

Copyright (c) 2018 M.Y. Salema, A.Z. Mohamed. This is an open access article distributed under the Creative Commons Attribution License, which permits unrestricted use, distribution, and reproduction in any medium, provided the original work is properly cited. 